\title{
Comparison between Agrifood and Other Priority Sectors in N. Greece and S. Bulgaria towards Their Environmental and Sustainability Improvement
}

\author{
Anastasia Martzopoulou ${ }^{1, *}$, Vasileios Firfiris ${ }^{2}$ \\ ${ }^{1}$ Department of Urban and Regional Planning, Faculty of Engineering, Aristotle University of Thessaloniki, Greece \\ ${ }^{2}$ Department of Agricultural Engineering, School of Agriculture, Aristotle University of Thessaloniki, Greece
}

Copyright $\bigcirc 2019$ by authors, all rights reserved. Authors agree that this article remains permanently open access under the terms of the Creative Commons Attribution License 4.0 International License

\begin{abstract}
For the comparable valuation of the manufactural activities between regions and sectors, methods of statistical analysis are used to define significant differences in terms of competitiveness, environmental load, sustainability and eco-productivity. The data was obtained from manufacturing industries (Small and Medium Enterprises) operating in Northern Greece and South Bulgaria. The statistical analysis is based on available emergy indices produced with emergy analysis. The results of the statistical analysis show that: (a) no significant differences were found between the manufacturing sectors examined, (b) the competitiveness of the manufacturing sector in S. Bulgaria significantly surpass that of N. Greece, under the current conditions in terms of labor and services compensation, (c) an elasticity of the environmental consciousness exists in S. Bulgaria in contrast to that of $\mathrm{N}$. Greece, (d) the low labor compensation does not lend any significant superiority to $\mathrm{S}$. Bulgaria in terms of the sustainability of its manufacturing industry, (e) from the eco-productivity statistical analysis becomes clear that the three main production factors, the labor, capital and energy, are better exploited in N. Greece than in S. Bulgaria.
\end{abstract}

Keywords Emergy Indices, Competitiveness, Environmental Load, Sustainability, Eco-productivity

\section{Introduction}

In European Union, the globalization was accompanied by a reinstallation of many productive and innovative activities in countries of low labor cost [1]. This research work was inspired by the abovementioned fact since a serious movement of several industrial and enterprising activities in the Greek borderlands, such as Central
Macedonia and East Macedonia - Thrace, in Greece as well as the nearby regions of neighboring countries, such as Bulgaria was observed. Usually, this kind of reinstallation of many financial activities is followed by a great impact on regional, national and sectoral indices. For example, the presence of the secondary sector of production in the region of Central Macedonia and especially in Thessaloniki it appears to be very beneficial, since it contributes to about $30 \%$ of the GNP (Gross National Product) and 20\% of the Gross Added Value of Greece.

The choice of the neighboring regions of Greece and Bulgaria appears to have a special interest for the comparable evaluation of agri-food and other manufacturing activities, due to many similarities and differences, which characterize them. A similarity that characterizes the neighboring regions of Greece and Bulgaria is the homogeneity of the demographic profile; the aging of the population resulting in the reduced workforce as well as the abandonment of the rural areas to the big cities. Also, homogeneity is observed in terms of environmental characteristics. The area is rich in natural resources, including rivers, forests, protected areas, and is considered one of the most ecologically sensitive areas of the Mediterranean. As regards economic data, the sector that appears to play a significant role in these areas and in terms of contributing to GDP is tertiary, while the secondary is also considered to be developed.

However, great differences are found in the economic structure between Greece and Bulgaria. One of the main reason is due to the fact that both countries are in transition for economic, fiscal and institutional reform but for different causes. The distance in time of the two countries in the European Union has resulted in a delay from the Bulgarian side to conform with the directives and regulations adding a further advantage to the Bulgarian companies. The low production costs due to the low wages of the workforce, as well as the favorable tax and 
bureaucratic regime, are considered as the most important incentives for the movement of many Greek enterprises from Drama, Serres and Thessaloniki to the area of Blagoevgrad.

The investigated industries are SMEs (Small and Medium Enterprises), which operate in two regions of Northern Greece as well as in two regions of South Bulgaria, during the year 2011. These regions are:

a Northern Greece: i. The region of Central Macedonia: including the areas of Thessaloniki, Pieria, Kilkis and Serres. ii. The region of Eastern Macedonia-Thrace: including the areas of Drama, Kavala, Xanthi, Rodopi and Evros.

b South Bulgaria: i. The region of Blagoevgrad. ii The region of Kardjali. These two regions are examined as one, due to the common characteristics they appear.

The above regions are characterized by the fact that they include a complicated network of energy, materials and information and they depend upon the sources and services, which are offered by their biosphere similarly to natural ecosystems. For these reasons the emergy analysis produce a proper way to evaluate the total eco-productivity of each one of the regions examined [2]. The raw data referred to the examined manufacturing industries was collected from several manufacturing industries from Northern Greece and Bulgaria. This data is actually the product of an investigation and detailed audits analysis for the needs of a project entitled "Cross Border Implementation of Innovative Cost Cutting Technologies-CROSSINNOCUT", as a part of which the present work can be considered. The examined manufacturing industries are mainly activated in the following sectors: Food/Drinks, Metals/Wood, Chemical/Plastics, Fabric/Clothing, Electric/Electronics, Building materials \& machinery. A percentage of about $90 \%$ of the total number of those industries belong to very small industries with a number of personnel below 10 persons. From the above industries, 30 belong to the region of C. Macedonia, 20 to E. Macedonia-Thrace and 16 to the regions of S. Bulgaria.

\section{Materials and Methods}

Emergy analysis was introduced by H. T. Odum [3] and it is used in this investigation as a modern and holistic method (Figure 1), to investigate the effect of renewable, non-renewable and financial inputs as well as the waste financial output produced on the sustainability of manufacturing industries. Emergy analysis offers the possibility of linking the utility that can occur in an industrial activity, since energy and environmental management are applied, in a way, which can make clear the advantage gained by "environmentally conscious enterprises", such as the food industries because these industries have interesting similarities with the natural ecosystems [4]. This is due to the fact, that both systems make use of energy and raw materials and they transform them into products and wastes [5].

The quantitative primary data was collected and classified in two ways: $a$. according to the region and $b$. according to the sector of activity, under the condition that the number of enterprises in any case is above five. The primary data used in the emergy analysis of the examined and compared industries are related to:

- $\quad$ The renewable inputs (R)

- $\quad$ The non-renewable inputs (N), (electricity (N1), Oil (N2), LPG (N3) and Natural Gas (N4)

- Financial inputs (F), (labor cost (F1), service and maintenance cost (F2), cost of market inputs (F3) and waste treatment cost (F4)

- $\quad$ Polluting gas emissions (W1) and waste production (W2)

- Annual turnover $(\mathrm{T})$

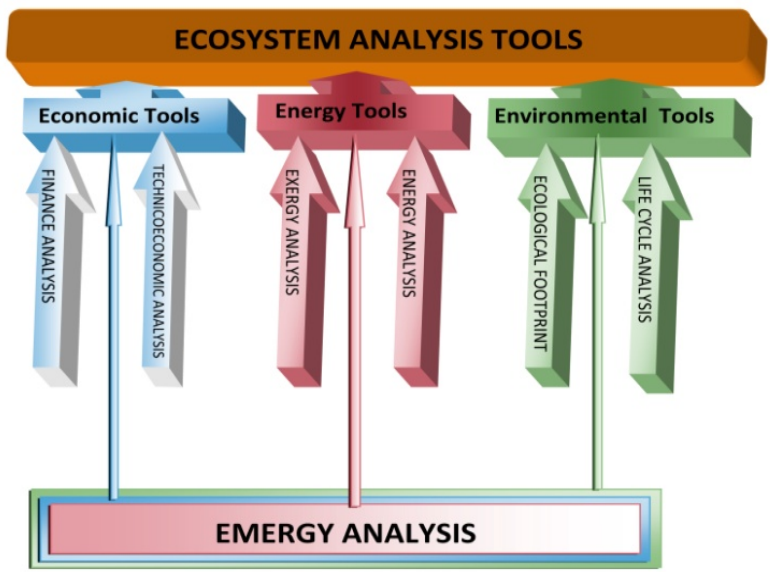

Figure 1. Schematic diagram of the main ecosystems' analysis diagnostic tools [6]

The emergy analysis is based on the calculation of the emergy indices: (a) EYR: Emergy Yield Ratio which expresses the competitiveness, (b) ELR: Environmental Load Ratio which expresses the environmental impact, (c) EIS: Emergy Index of Sustainability which expresses the average degree of sustainability and (d) the Emergy eco-Productivity Index (EPI), which expresses the influence of the monetary, non-monetary and renewable inputs, in the final economic product. The results of the above indices calculations are used as the data in this work. The values of these emergy indices, as given by a research work of Martzopoulou [4], are shown in Tables 1, 2 and 3. The comparable evaluation and the finding of significant differences of the examined sectors between and within the regions were based on the following statistical analyses:

1. Calculation of the regression equation and the coefficient of determination of the emergy indices 
versus the annual turnover for the industrial sectors activated in each of the regions examined.

2. Analyses of Variance (ANOVA) to define significant differences between the main five manufacturing sectors examined, in terms of competitiveness, environmental distress, Sustainability and eco-productivity, for probability value $\mathrm{p}<0,05$.

3. Analysis of Variance (ANOVA) to define significant differences between the three regions examined, in terms of competitiveness, environmental distress, sustainability and eco-productivity, value $\mathrm{p}<0,05$.
4. All the above Analyses of Variance are also repeated without the influence of the services (maintenance and marketing expenses) and labor costs.

The afore-mentioned statistical analyses are used to derive conclusions referring to (a) the diversification between the regions as well the industrial sectors of the SMEs examined, and (b) the influence of the geographical regions, according to their local financial policies exercised.

Table 1. Emergy indices of Central Macedonia calculated with and without the cost of labor and services [4].

\begin{tabular}{|c|c|c|c|c|c|c|c|c|c|}
\hline & SMEs categories & EYR & $\mathrm{EYR}_{\text {-LS }}$ & ELR & $\mathrm{ELR}_{\text {-LS }}$ & EIS & EIS $_{\text {-LS }}$ & EPI & EPI $_{\text {-LS }}$ \\
\hline 1 & Food/drinks1 & 1,193 & 1,553 & 1,233 & 1,691 & 0,918 & 0,918 & 0,784 & 1,732 \\
\hline 2 & Food/drinks 2 & 1,178 & 2,238 & 1,206 & 2,550 & 0,878 & 0,977 & 1,393 & 5,115 \\
\hline 3 & Food/drinks3 & 1,022 & 1,045 & 1,027 & 1,054 & 0,991 & 0,996 & 1,266 & 2,490 \\
\hline 4 & Food/drinks4 & 1,086 & 1,187 & 1,101 & 1,221 & 0,972 & 0,987 & 1,037 & 2,068 \\
\hline 5 & Food/drinks5 & 1,025 & 1,044 & 1,031 & 1,052 & 0,995 & 0,992 & 0,845 & 1,422 \\
\hline 6 & Food/drinks 6 & 1,057 & 1,074 & 1,064 & 1,084 & 0,993 & 0,991 & 0,953 & 1,225 \\
\hline 7 & Food/drinks7 & 1,063 & 1,118 & 1,075 & 1,142 & 0,988 & 0,979 & 1,362 & 2,434 \\
\hline 8 & Food/drinks 8 & 1,150 & 1,225 & 1,182 & 1,275 & 0,973 & 0,961 & 1,214 & 1,722 \\
\hline 9 & Fabric/Clothing 1 & 1,158 & 1,437 & 1,148 & 1,408 & 1,008 & 1,020 & 1,307 & 2,961 \\
\hline 10 & Fabric/Clothing 2 & 1,076 & 1,171 & 1,086 & 1,195 & 0,991 & 0,980 & 1,681 & 3,483 \\
\hline 11 & Metals/Wood 1 & 1,032 & 1,039 & 1,039 & 1,048 & 0,993 & 0,992 & 0,990 & 1,198 \\
\hline 12 & Metals/Wood 2 & 1,223 & 1,454 & 1,276 & 1,574 & 0,959 & 0,923 & 1,115 & 1,912 \\
\hline 13 & Metals/Wood 3 & 1,028 & 1,075 & 1,034 & 1,092 & 0,994 & 0,985 & 1,225 & 3,113 \\
\hline 14 & Metals/Wood 4 & 1,017 & 1,042 & 1,024 & 1,059 & 0,993 & 0,984 & 0,962 & 2,306 \\
\hline 15 & Metals/Wood 5 & 1,106 & 1,280 & 1,121 & 1,322 & 0,987 & 0,968 & 2,148 & 4,935 \\
\hline 16 & Metals/Wood 6 & 0,912 & 0,841 & 1,898 & 3,800 & 0,481 & 0,221 & 0,871 & 1,721 \\
\hline 17 & Metals/Wood 7 & 1,090 & 1,134 & 1,109 & 1,421 & 0,983 & 0,943 & 0,563 & 1,728 \\
\hline 18 & Metals/Wood 8 & 1,024 & 1,032 & 1,030 & 1,040 & 0,995 & 0,993 & 0,979 & 1,304 \\
\hline 19 & Metals/Wood 9 & 1,129 & 1,176 & 1,160 & 1,219 & 0,974 & 0,965 & 0,991 & 1,297 \\
\hline 20 & Metals/Wood 10 & 1,014 & 1,020 & 1,031 & 1,046 & 0,983 & 0,976 & 1,086 & 1,599 \\
\hline 21 & Electric/Electronic 1 & 1,020 & 1,030 & 1,023 & 1,035 & 0,997 & 0,995 & 0,960 & 1,405 \\
\hline 22 & Electric/Electronic 2 & 1,091 & 1,753 & 1,110 & 1,985 & 0,982 & 0,883 & 1,323 & 6,845 \\
\hline 23 & Chemical/Plastics 1 & 1,030 & 1,042 & 1,036 & 1,050 & 0,994 & 0,992 & 0,943 & 1,316 \\
\hline 24 & Chemical/Plastics 2 & 1,473 & 2,129 & 1,542 & 2,345 & 0,995 & 0,908 & 0,780 & 1,322 \\
\hline 25 & Chemical/Plastics 3 & 1,003 & 1,005 & 1,003 & 1,005 & 1,000 & 1,000 & 1,219 & 1,898 \\
\hline 26 & Chemical/Plastics 4 & 1,003 & 1,003 & 1,003 & 1,004 & 1,000 & 0,999 & 1,123 & 1,253 \\
\hline 27 & Chemical/Plastics 5 & 1,004 & 1,005 & 1,035 & 1,041 & 0,970 & 0,965 & 1,159 & 1,366 \\
\hline 28 & Chemical/Plastics 6 & 1,022 & 1,079 & 1,010 & 1,034 & 1,012 & 1,043 & 0,883 & 3,076 \\
\hline 29 & Chemical/Plastics 7 & 1,013 & 1,017 & 1,014 & 1,019 & 0,998 & 0,998 & 1,261 & 1,662 \\
\hline 30 & Creative/Printing & 1,141 & 1,468 & 1,174 & 1,598 & 0,972 & 0,918 & 0,809 & 2,083 \\
\hline
\end{tabular}



towards Their Environmental and Sustainability Improvement

Table 2. Emergy indices of East Macedonia-Thrace calculated with and without the cost of labor and services [4].

\begin{tabular}{|c|c|c|c|c|c|c|c|c|c|}
\hline & SMEs categories & EYR & $\mathrm{EYR}_{\text {-LS }}$ & ELR & $\mathrm{ELR}_{\text {-LS }}$ & EIS & EIS $_{\text {-LS }}$ & EPI & EPI $_{\text {-LS }}$ \\
\hline 1 & Food/drinks 9 & 1,078 & 1,098 & 1,093 & 1,117 & 0,986 & 0,983 & 1,121 & 1,382 \\
\hline 2 & Food/drinks 10 & 1,009 & 1,012 & 1,036 & 1,047 & 0,974 & 0,966 & 0,914 & 1,187 \\
\hline 3 & Food/drinks 11 & 1,146 & 1,179 & 1,145 & 1,177 & 1,001 & 1,001 & 0,967 & 1,153 \\
\hline 4 & Food/drinks 12 & 1,081 & 1,118 & 1,096 & 1,139 & 0,981 & 0,981 & 0,881 & 1,233 \\
\hline 5 & Food/drinks 13 & 1,474 & 1,668 & 1,599 & 1,864 & 0,972 & 0,895 & 0,563 & 0,701 \\
\hline 6 & Food/drinks 14 & 1,205 & 1,362 & 1,253 & 1,454 & 0,962 & 0,936 & 1,831 & 2,857 \\
\hline 7 & Food/drinks 15 & 1,036 & 1,053 & 1,037 & 1,054 & 0,999 & 0,999 & 1,707 & 2,451 \\
\hline 8 & Food/drinks 16 & 1,045 & 1,073 & 1,047 & 1,077 & 0,998 & 0,997 & 0,748 & 1,180 \\
\hline 9 & Metals/Wood 11 & 1,132 & 1,438 & 1,152 & 1,514 & 0,983 & 0,950 & 1,069 & 2,874 \\
\hline 10 & Metals/Wood 12 & 1,062 & 1,092 & 1,076 & 1,113 & 0,987 & 0,981 & 1,049 & 1,515 \\
\hline 11 & Metals/Wood 13 & 1,001 & 1,001 & 1,424 & 1,514 & 0,703 & 0,661 & 1,265 & 1,478 \\
\hline 12 & Metals/Wood 14 & 1,038 & 1,068 & 1,042 & 1,076 & 0,996 & 0,993 & 1,031 & 1,809 \\
\hline 13 & Metals/Wood 15 & 0,972 & 0,947 & 1,104 & 1,214 & 0,881 & 0,780 & 0,777 & 1,542 \\
\hline 14 & Metals/Wood 16 & 1,528 & 2,045 & 1,622 & 2,279 & 0,942 & 0,897 & 1,784 & 2,639 \\
\hline 15 & Electric/Electronic 3 & 1,035 & 1,176 & 1,043 & 1,220 & 0,992 & 0,964 & 1,252 & 5,584 \\
\hline 16 & Electric/Electronic 4 & 1,088 & 1,094 & 1,107 & 1,114 & 0,983 & 0,982 & 0,800 & 0,848 \\
\hline 17 & Chemical/Plastics 8 & 1,897 & 2,971 & 1,923 & 3,050 & 0,987 & 0,974 & 1,625 & 2,281 \\
\hline 18 & Building materials & 1,847 & 2,915 & 2,021 & 3,499 & 0,914 & 0,833 & 0,294 & 0,422 \\
\hline 19 & Car repair & 0,996 & 0,994 & 1,027 & 1,045 & 0,970 & 0,951 & 0,887 & 1,441 \\
\hline 20 & Tire retreading & 1,464 & 1,956 & 1,598 & 2,306 & 0,916 & 0,848 & 0,455 & 0,701 \\
\hline
\end{tabular}

Table 3. Emergy indices of South Bulgaria calculated with and without the cost of labor and services [4].

\begin{tabular}{|c|c|c|c|c|c|c|c|c|c|}
\hline & SMEs categories & EYR & EYR $_{\text {LS }}$ & ELR & ELR-LS & EIS & EIS $_{\text {-LS }}$ & EPI & EPI-LS \\
\hline 1 & Food/drinks 17 & 1,338 & 1,516 & 1,424 & 1,659 & 0,940 & 0,913 & 0,936 & 1,261 \\
\hline 2 & Food/drinks 18 & 1,671 & 1,769 & 1,845 & 1,978 & 0,906 & 0,894 & 0,738 & 0,799 \\
\hline 3 & Food/drinks 19 & 1,163 & 1,227 & 1,196 & 1,277 & 0,972 & 0,961 & 0,966 & 1,280 \\
\hline 4 & Fabric/Clothing 3 & 1,446 & 1,522 & 1,567 & 1,668 & 0,923 & 0,912 & 0,646 & 0,718 \\
\hline 5 & Fabric/Clothing 4 & 1,151 & 1,163 & 1,186 & 1,201 & 0,971 & 0,968 & 0,837 & 0,897 \\
\hline 6 & Fabric/Clothing 5 & 1,175 & 1,205 & 1,193 & 1,226 & 0,985 & 0,983 & 0,883 & 1,006 \\
\hline 7 & Fabric/Clothing 6 & 1,149 & 1,299 & 1,169 & 1,346 & 0,983 & 0,965 & 0,806 & 1,432 \\
\hline 8 & Fabric/Clothing 7 & 1,123 & 1,247 & 1,142 & 1,289 & 0,983 & 0,967 & 0,832 & 1,501 \\
\hline 9 & Fabric/Clothing 8 & 1,207 & 1,409 & 1,240 & 1,486 & 0,973 & 0,948 & 0,774 & 1,312 \\
\hline 10 & Fabric/Clothing 9 & 1,121 & 1,645 & 1,144 & 1,818 & 0,979 & 0,905 & 0,654 & 2,383 \\
\hline 11 & Metal/timber 17 & 1,050 & 1,108 & 1,054 & 1,117 & 0,996 & 0,992 & 0,985 & 2,008 \\
\hline 12 & Metal/timber 18 & 1,122 & 1,202 & 1,149 & 1,249 & 0,976 & 0,962 & 0,860 & 1,328 \\
\hline 13 & Metal/timber 19 & 1,029 & 1,058 & 1,342 & 1,795 & 0,767 & 0,589 & 0,838 & 1,603 \\
\hline 14 & Electric/Electronic 5 & 1,252 & 1,572 & 1,307 & 1,717 & 0,958 & 0,916 & 0,747 & 1,349 \\
\hline 15 & Building materials 2 & 3,280 & 3,596 & 4,721 & 5,446 & 0,695 & 0,660 & 0,364 & 0,378 \\
\hline 16 & Mushrooms & 1,322 & 1,531 & 2,759 & 5,859 & 0,479 & 0,261 & 0,371 & 0,528 \\
\hline
\end{tabular}




\section{Results and Discussion}

\subsection{The Influence of the Total Inputs to the Annual Turnover of the SMEs in Each Region}

The measurements of the non-renewable and renewable energy, labor, services, market, waste management emergy flows were compared with the gross annual income of the SMEs, separately for each region. The assessments after the regressions show a very close linear relation between the emergy flows and the gross annual turnover, for the three regions. The calculated high values of the coefficient of determination conclude this relation. The regression equations and the corresponding coefficients of determination are shown in Figures 2, 3 and 4 . The three regressions, found to have almost same slopes, which means that inputs are almost equally exploited in the three regions.

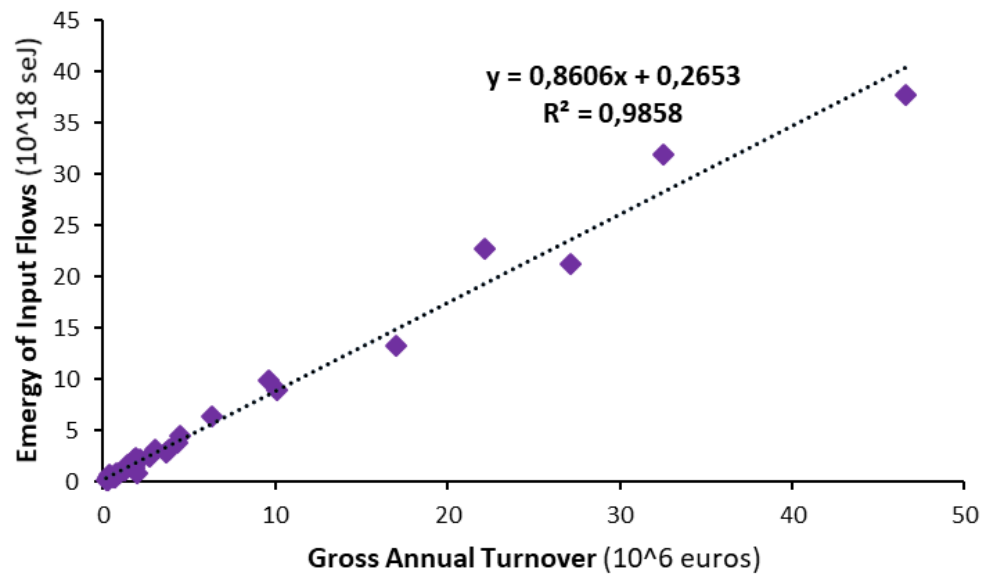

Figure 2. Annual turnover vs. Emergy flows in the region of Central Macedonia

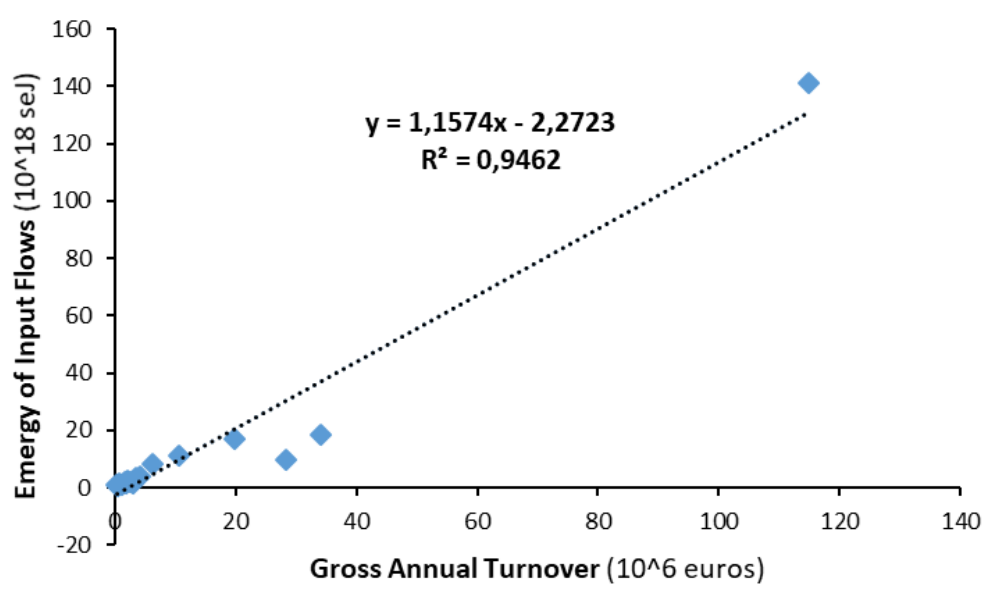

Figure 3. Annual turnover vs. Emergy flows in the region of East Macedonia-Thrace

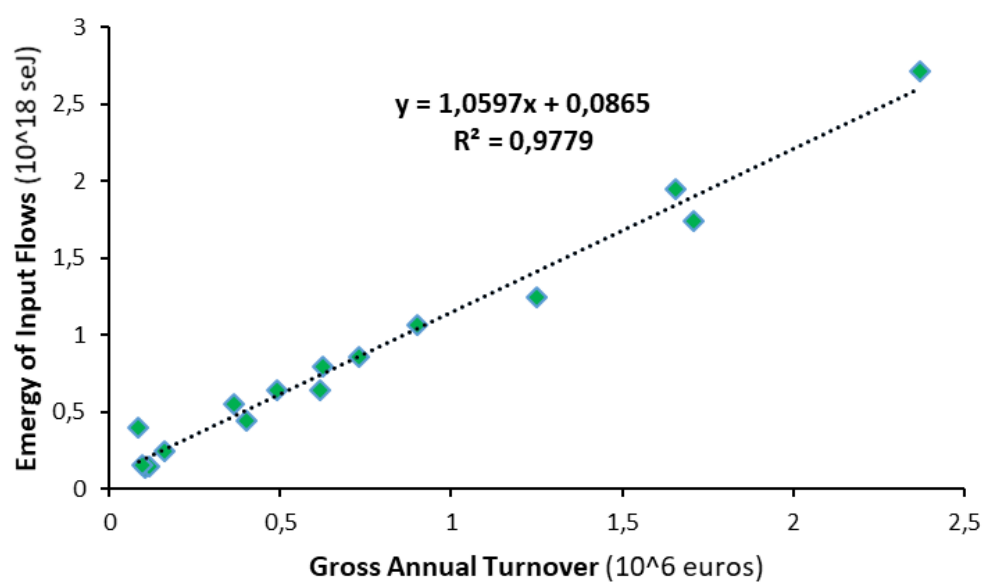

Figure 4. Annual turnover vs. Emergy flows in the region of South Bulgaria 


\subsection{Comparable Evaluation of the Industrial Groups by Sector}

The five more important out of the six manufacturing sectors, mentioned in the introduction and operating within the three regions, are evaluated and compared. These five sectors are the Food/Drinks, Metals/Wood, Chemical/ Plastics, Fabric/Clothing, Electric/Electronics. For this reason, the ANOVA executed to find significant differences between the sectors shows the absence of any significant difference, either taking into account labor and services costs or not. However, emergy indices mean values of each for the five sectors with and without accounting the afore-mentioned costs are used for a simple comparison of the industrial groups by sector.

(a) Competitiveness: The diagrams in Figure 5 appear a relative superiority of the chemical/plastics sector over the other four sectors, especially when labor and services cost are not accounted, and relative deficient of the metal/wood sector, in terms of competitiveness. In the case of accounting labor costs and services, fabric/clothes sector looks to surpass chemical/plastics but this can be explained by the fact that the latter sector spends more for expertise in staff and services.

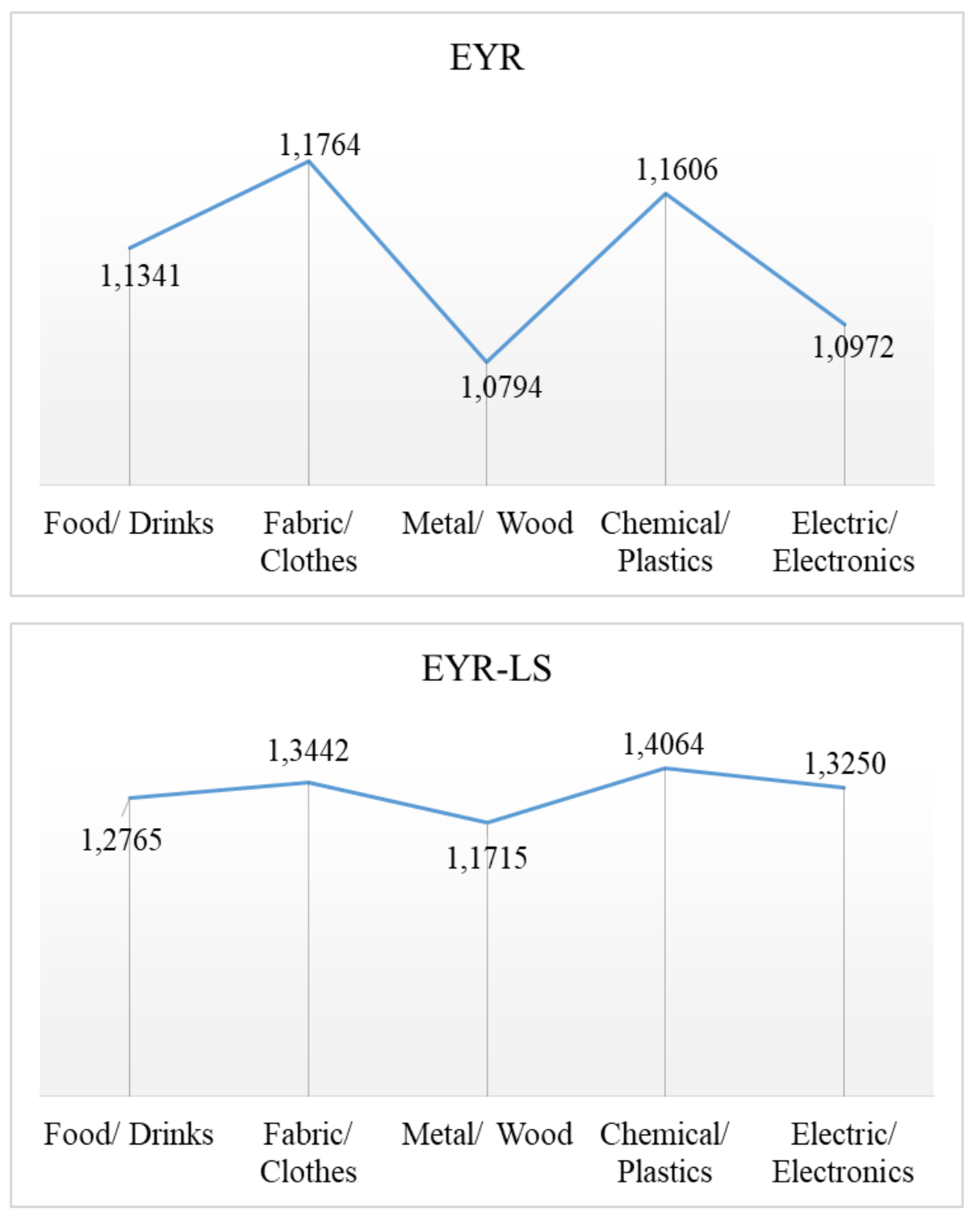

Figure 5. Diagrams of the mean emergy index values of competitiveness with (EYR) and without the services and labor costs (EYR-SL) 
(b) Environmental impact: The diagrams of environmental load indices (Figure 6) present a settled high environmental pollution impact of the chemical/plastics and metal/wood sectors. In contrast, the sector of Electric/Electronics appears as the most environmentally clean sector.

(c) Sustainability: The Figure 7 of the sustainability index diagrams shows the sector of electric/electronics in a steadily high position and the sector of metal/wood in a relatively low position. The other three sectors appear to be affected by local conditions of labor and services costs.

(d) Eco-productivity: The comparison of the eco-productivity indices of the sectors examined is illustrated in the diagrams of the Figure 8. According to these diagrams the sectors of metals/wood and electric/electronics are appeared in a steadily middle to high position, in terms of eco-productivity, while the sector of fabric/clothing appears a steadily low position. The other two sectors seem to be affected by local conditions of labor and services costs.
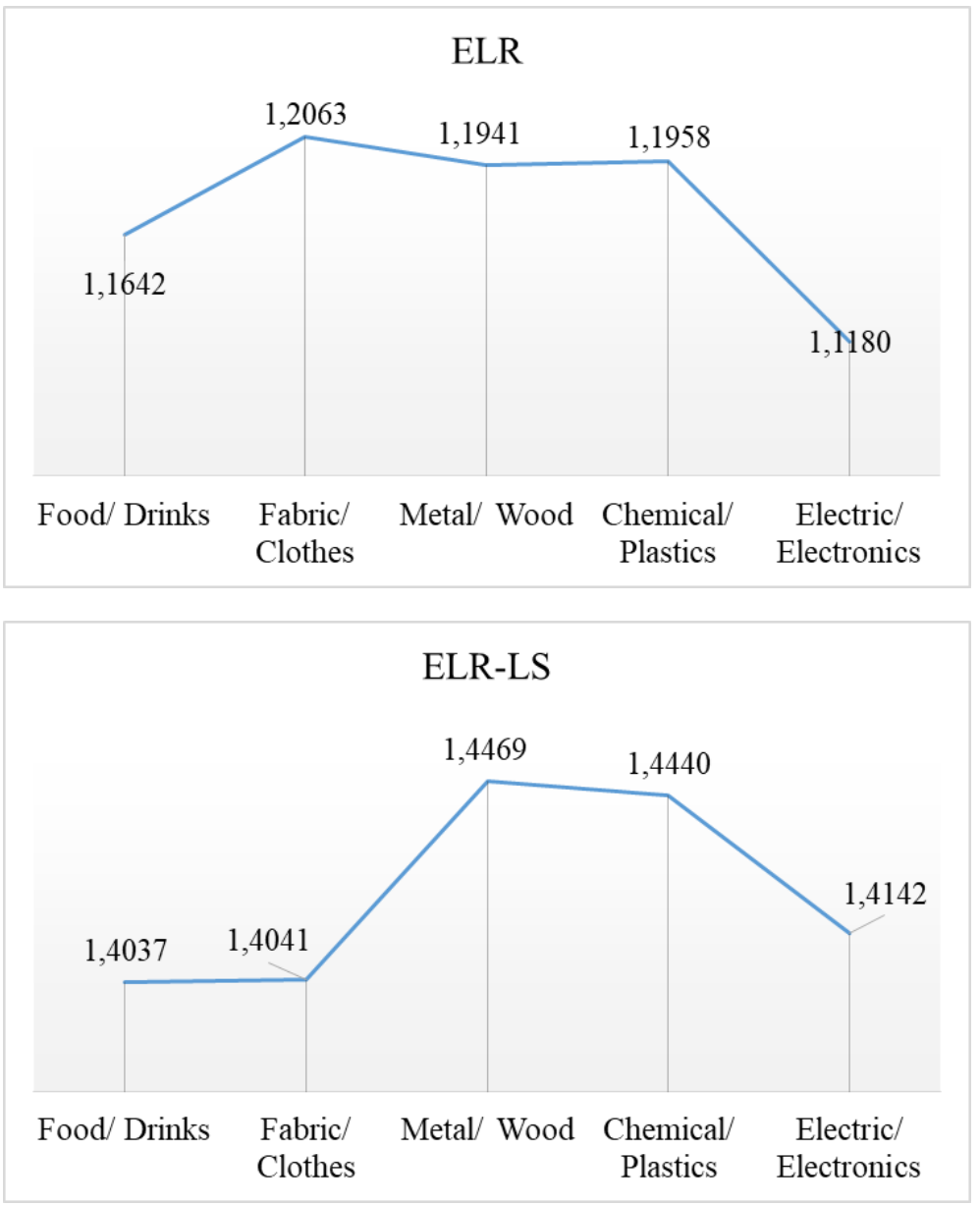

Figure 6. Diagrams of the mean emergy index values of environmental load with (ELR) and without the labor and services costs (ELR-LS)

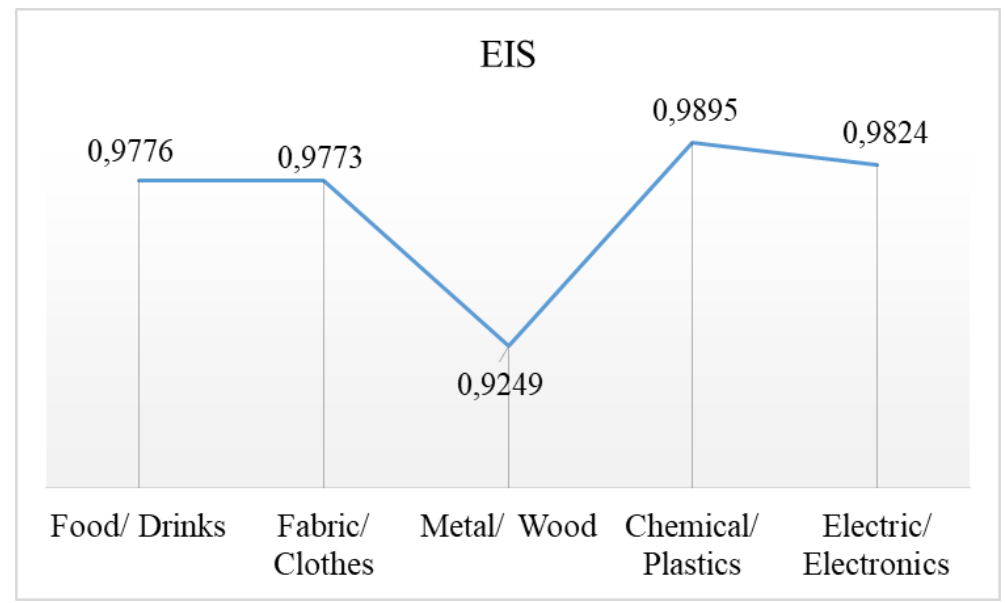




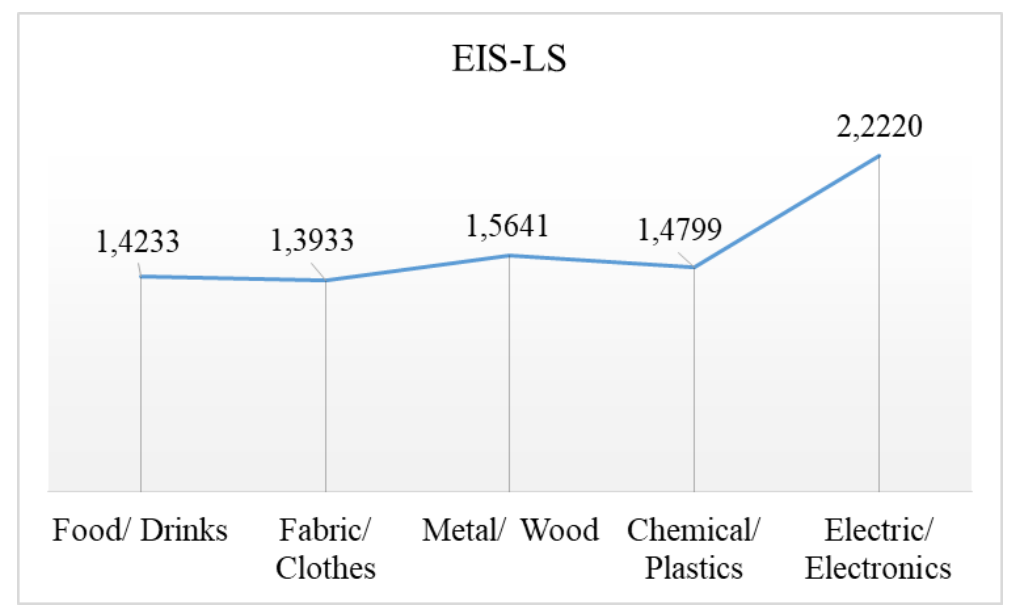

Figure 7. Diagrams of the mean emergy index values of sustainability with (EIS) and without the labor and services costs (EIS-LS)
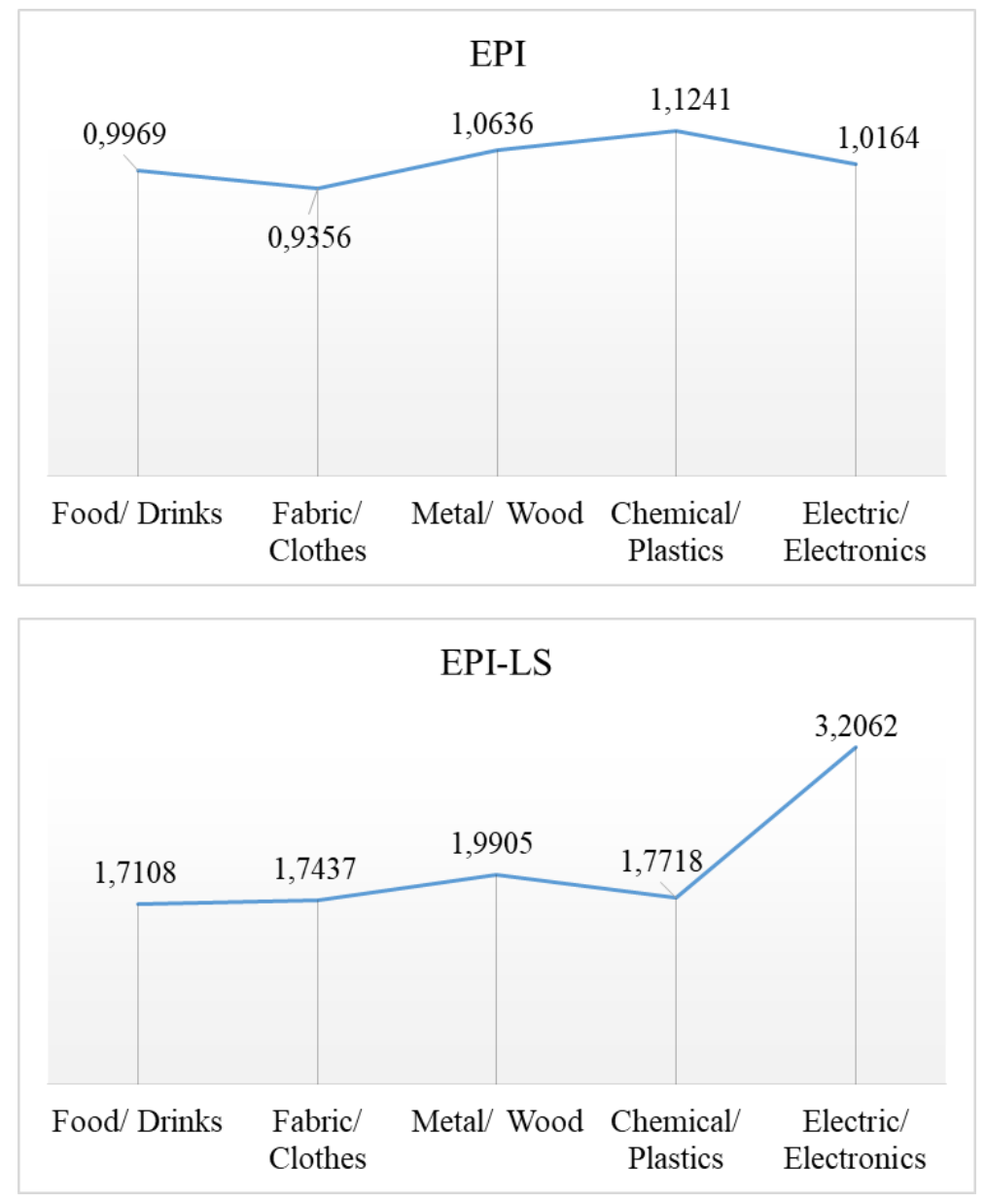

Figure 8. Diagrams of the mean emergy index values of eco-productivity with (EPI) and without the labor and services costs (EPI-LS)

\subsection{Comparable Evaluation of the Industrial Groups by Region}

The following statistical analyses lead to the comparable evaluation of the influence of the region to the competitiveness, the environmental impact, sustainability and the eco- productivity of the manufacturing enterprises (SMEs) installed in each of the three regions, in two ways, (a) with the entry of labor, services, marketing and maintenance costs and (b) without them. The statistical analysis includes (i) an analysis of variance (ANOVA) to find out significant differences (Table 4), (ii) the means diagram of the variables (EYR, ELR, EIS and EPI) of the SMEs groups in each region and (iii) a post hoc analysis with use of least significant differences for $95 \%$ probability value, to specify the significant differences 
(Table 5) of each variable between the regions.

(a) Competitiveness (EYR). The ANOVA shows significant differences (Table 4) between the regions with reference to competitiveness. The mean values of EYR and EYR-SL in each region is illustrated in Figure 9. The post hoc analysis shows that the significant differences exist only between the manufacturing industries of Central Macedonia and South Bulgaria.

However, the ANOVA in Table 5 shows no significant difference in competitiveness between the regions, when the cost of labor (L) and services (S) is not accounted. The above statistical analyses show that the South Bulgarian region gains a supremacy over the Greek regions, in terms of competitiveness. Nevertheless, post hoc analysis showed significant difference only between S. Bulgaria (lowest labor-services cost) and Central Macedonia, (highest costs). On the other hand, no significant differences appear when the cost of labor (L) and services (S) is not taken into account. (b) Environmental impact (ELR). The ANOVA shows significant differences (Table 4) between the regions with reference to environmental impact. The post hoc analysis shows that the significant differences exist between the manufacturing industries of Central Macedonia and South Bulgaria (Table 5), while a marginal existence of statistical difference appears between the S. Bulgaria and East Macedonia-Thrace, with reference to environmental impact, when labor and services are included. Also, in the ANOVA of Table 4 no significant differences appear, in the absence of services and labor costs. The mean values diagram of ELR and ELR-SL, in each region, are illustrated in Figure 10, where it can be seen a lower environmental distress in the $\mathrm{N}$. Greek regions compared with the S. Bulgaria. The above statistical analyses of ELR may conclude that a more elastic environmental consciousness exists in Bulgaria compared to Greece.

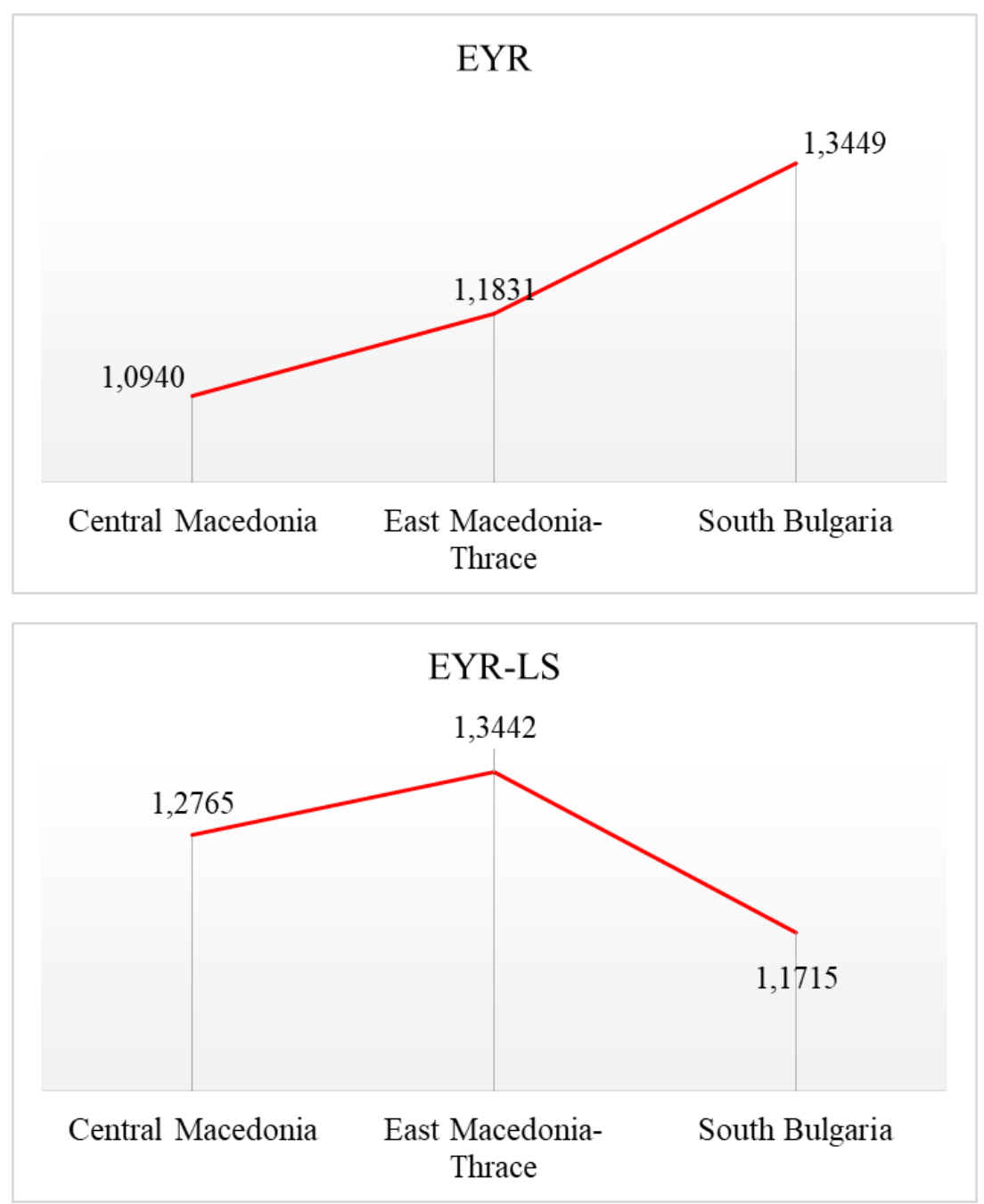

Figure 9. Competitiveness diagrams of SMEs per region with (EYR) and without the services and labor costs (EYR-SL) 

towards Their Environmental and Sustainability Improvement

Table 4. ANOVA table of the significant differences of the SMEs variables between the three regions.

\begin{tabular}{|c|c|c|c|c|c|}
\hline $\begin{array}{c}\text { Depended Variable } \\
\text { Between Regions }\end{array}$ & Sum of Squares(ss) & $\begin{array}{c}\text { Degree of freedom } \\
(\mathrm{df})\end{array}$ & Mean Square & $\mathrm{F}$ & $\begin{array}{c}\text { Significance } \\
\text { P }\end{array}$ \\
\hline EYR & 0,765 & 2 & 0,382 & 3,937 & 0,024 \\
\hline ELR & 2,259 & 2 & 1,129 & 4,495 & 0,015 \\
\hline EPI & 1,227 & 2 & 0,614 & 5,609 & 0,006 \\
\hline EPI-LS & 11,672 & 2 & 5,836 & 4,611 & 0,014 \\
\hline
\end{tabular}

Table 5. The post hoc analysis table to point out the significant differences of each variable between the regions.

\begin{tabular}{|c|c|c|c|c|c|c|c|}
\hline \multirow{2}{*}{$\begin{array}{l}\text { Depended } \\
\text { Variable }\end{array}$} & \multirow{2}{*}{ (I) Region } & \multirow{2}{*}{ (II) Region } & \multirow{2}{*}{$\begin{array}{c}\text { Mean differences } \\
\text { (I-II) }\end{array}$} & \multirow{2}{*}{ Std. Error } & \multirow{2}{*}{ Sig. } & \multicolumn{2}{|c|}{$\begin{array}{c}\text { Probability value } \\
\mathrm{P}<0,05\end{array}$} \\
\hline & & & & & & Lower Bound & Upper Bound \\
\hline $\begin{array}{l}\text { EYR } \\
\text { LSD }\end{array}$ & Central Macedonia & $\begin{array}{c}\text { South } \\
\text { Bulgaria }\end{array}$ & $-0,2705$ & 0,0965 & 0,007 & $-0,4633$ & $-0,0777$ \\
\hline \multirow{2}{*}{$\begin{array}{l}\text { ELR } \\
\text { LSD }\end{array}$} & \multirow[b]{2}{*}{ South Bulgaria } & Central Macedonia & 0,4624 & 0,1552 & 0,004 & 0,1523 & 0,7725 \\
\hline & & $\begin{array}{c}\text { East Macedonia \& } \\
\text { Thrace }\end{array}$ & 0,3461 & 0,1681 & 0,044 & 0,0102 & 0,6821 \\
\hline $\begin{array}{l}\text { EPI } \\
\text { LSD }\end{array}$ & South Bulgaria & Central Macedonia & $-0,3429$ & 0,1024 & 0,001 & $-0,5475$ & $-0,1383$ \\
\hline $\begin{array}{c}\text { EPI-LS } \\
\text { LSD }\end{array}$ & Central Macedonia & $\begin{array}{c}\text { South } \\
\text { Bulgaria }\end{array}$ & 1,0299 & 0,3483 & 0,004 & 0,3339 & 1,7259 \\
\hline
\end{tabular}

\section{ELR}

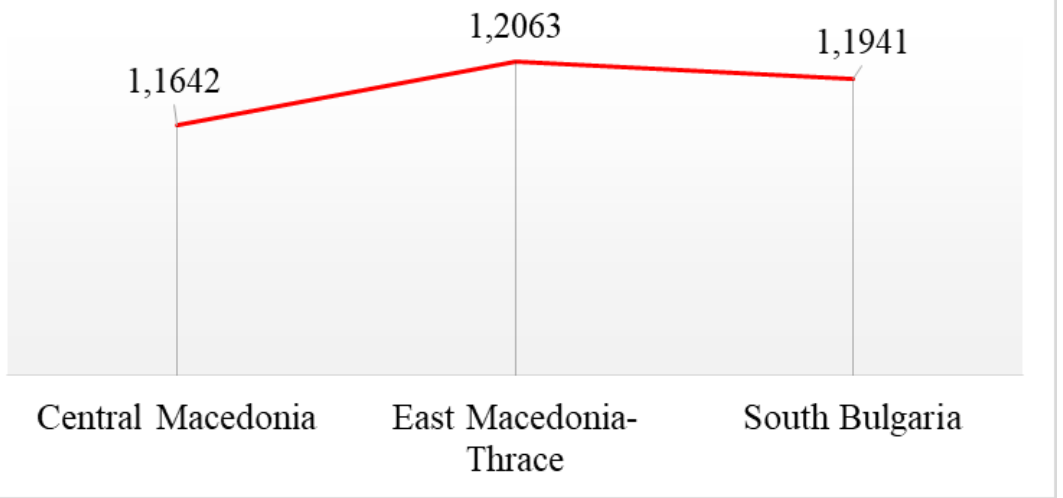

\section{ELR-LS}

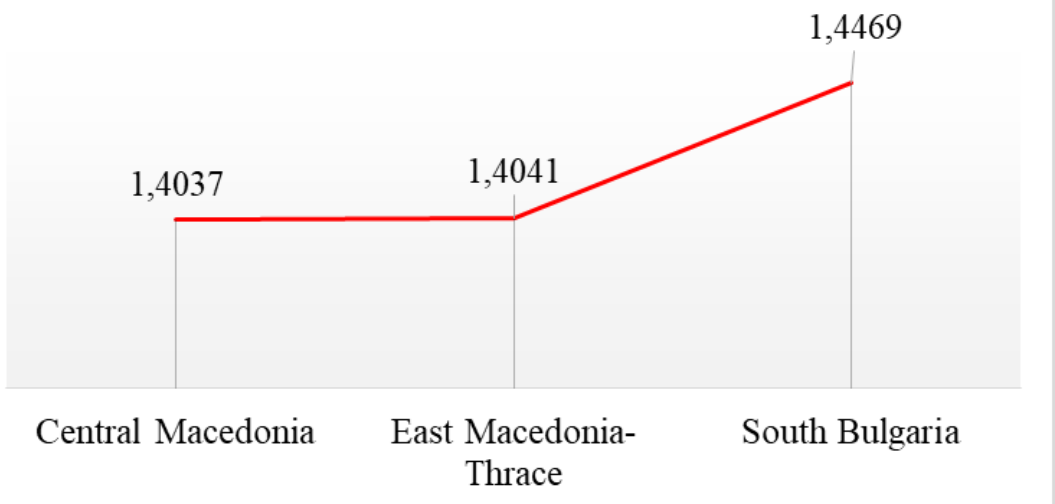

Figure 10. Environmental load diagrams of SMEs per region with (ELR) and without the services and labor costs (ELR-SL) 
(c) Sustainability (EIS). The emergy index of sustainability (EIS) is a division product of the emergy index of competitiveness (EYR) by the emergy index of environmental load (ELR). The ANOVA of the sustainability index of the three industrial groups by region examined, showed that no significant differences of the sustainability among the three regions exist, either accounting or not the services and labor costs (Table 4) and they are illustrated in Figure 11.

(d) Eco-productivity (EPI). The ANOVA of the emergy eco-productivity indices of the examined SMEs shows significant differences between the groups (Table 4), with and without the services and labor costs. The post hoc analysis (Table 5) resulted that significant differences exist between the regions of S. Bulgaria and C. Macedonia with reference to eco-productivity, when labor and services are included. In addition, significant differences were found in index EIS-LS, when services and labor are not accounted, only between the region of S. Bulgaria and C. Macedonia. The above differences are illustrated in the diagrams of Figure 12.

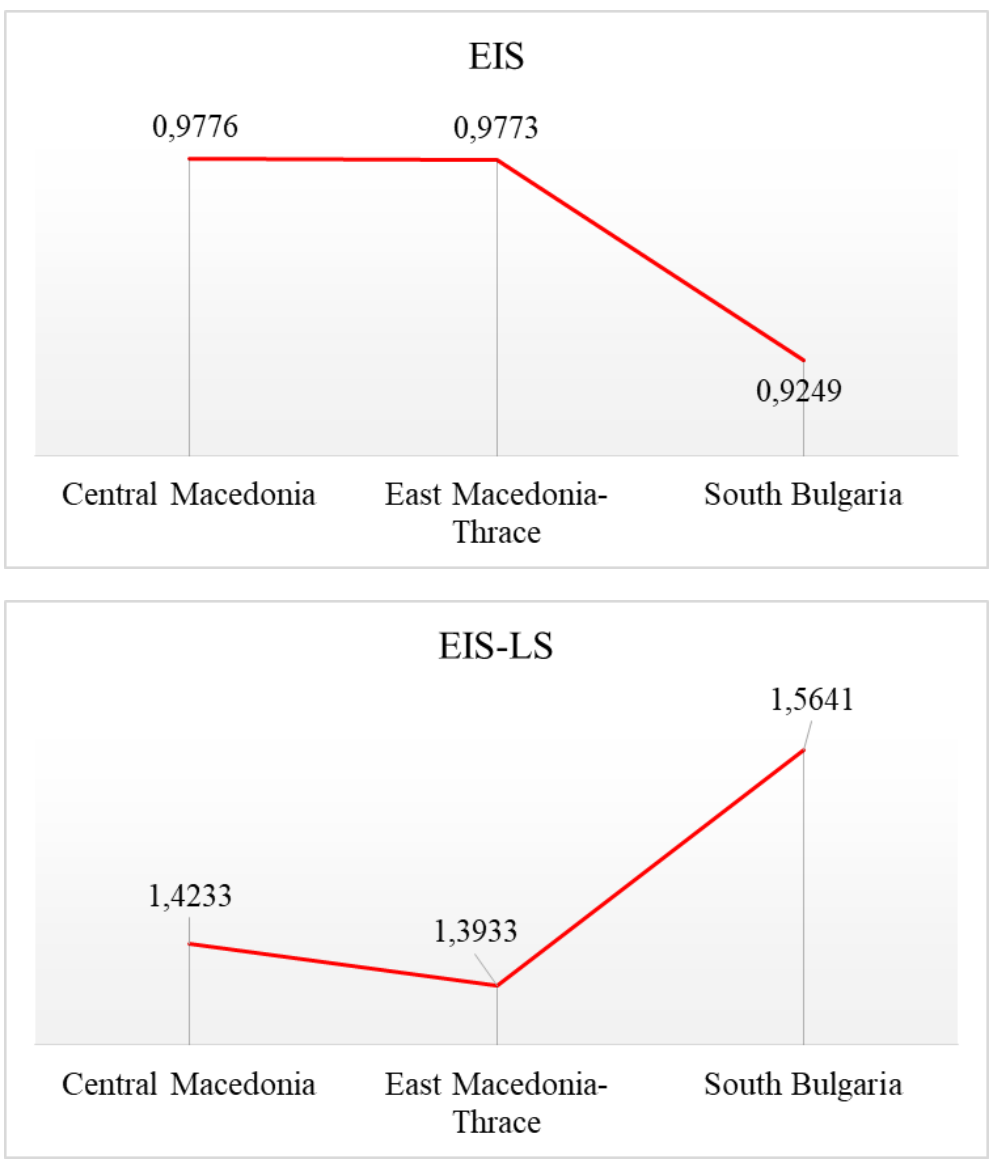

Figure 11. Sustainability diagram of SMEs per region with (EIS) and without the services and labor costs (EIS-SL)

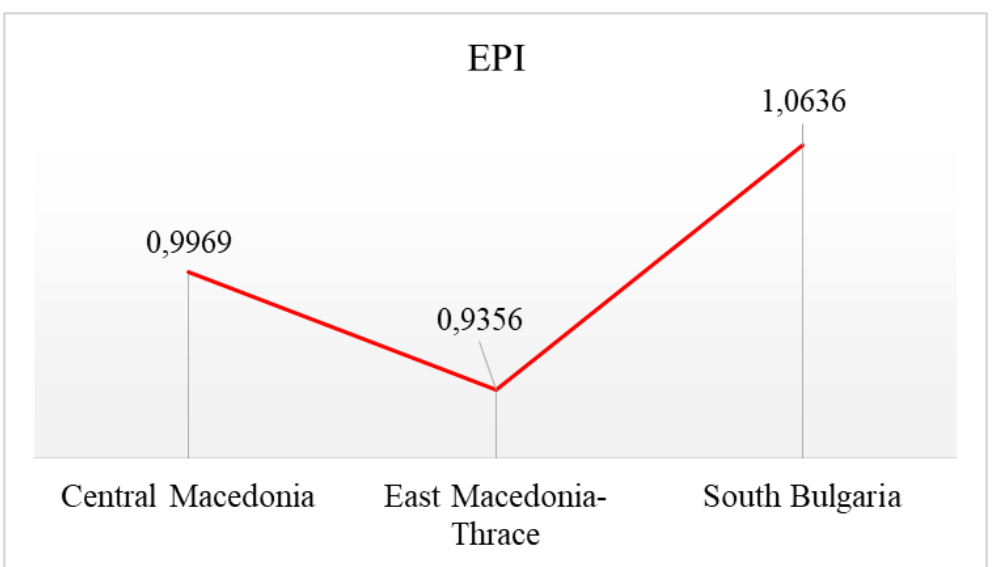




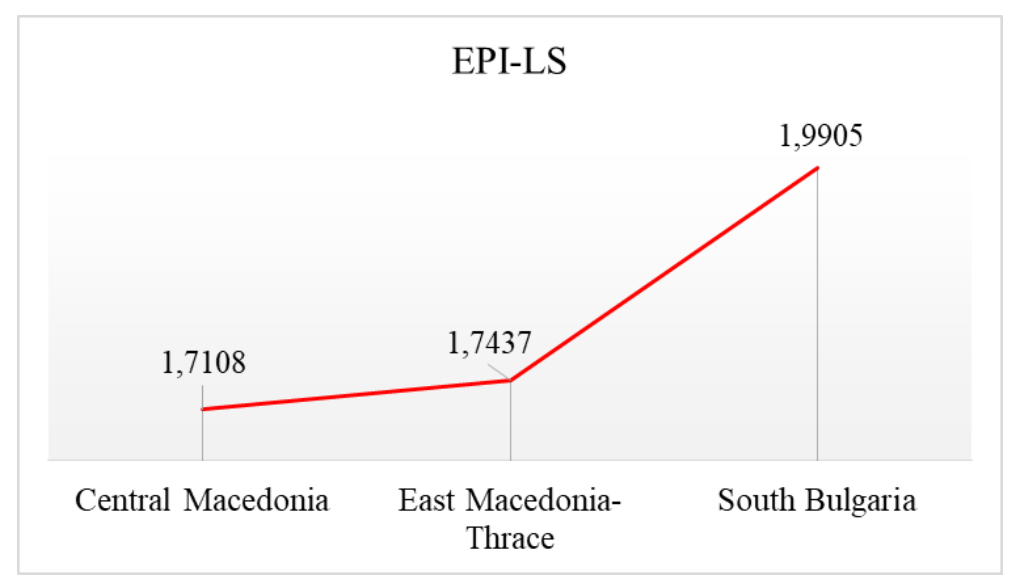

Figure 12. Eco-productivity diagrams of SMEs per region with (EPI) and without the services and labor costs (EPI-SL).

\section{Conclusions}

The results of this investigation led to the following conclusions:

a The regression analysis of the emergy index data for all the regions examined showed a similar slope and a very high coefficient of determination. These results draw the conclusion that the data used can be considered of high reliability, since the input flows proportionally affect the annual turnover.

b The results concerning the comparison between the regions lead to the conclusion that competitivity of Bulgaria exceeds this one of Greece, mainly due to the low labor and services costs. Nevertheless, some other factors, mainly financial, related with policies exercised by each country for strengthening the industrial production, affects, also, competitiveness. For example, the percentage of the total surcharge, including taxes, fees, etc., of the operational profit in Bulgaria at 2011 was 28,10\%, while in Greece was $46,80 \%$ [7] and this practice inversely affects the Greek competitiveness. On the other hand, the increasing exploitation of renewable energy sources in Greece is expected to improve the emergy index of competitiveness (EYR). The conclusion derived from this ANOVA is absolutely aligned with the results of another investigation, according to which, a similar index of competitiveness for Bulgaria was 4,16 and for Greece 3,92 at the same year 2011 [8].

c The results referred to the environmental distress caused by the industrial activities in the examined regions showed a significant negative picture in Bulgaria, compared with the neighboring Greek regions examined. These results were mainly due to the fact that Bulgaria, as a new member of the EU, may not fully adopted the European directives and rules for the environment. In contrast, the low environmental distress in Greece is probably due to the severe and frequent inspections, as well as the increasing use of alternative energy sources, which contribute to the decrease of emission and environmental pollution.

d The South Bulgarian manufacturing industries found to have no significant superiority in sustainability over the Greek ones, although the first appears with a lower labor and service cost. In contrast, the Central Macedonian manufacturing industries have the higher emergy index of sustainability, although they have the higher labor and service costs.

e The eco-productivity statistical analysis makes clear that the three basic factors of production (labor, capital and energy) are better exploited in the two Greek regions, than in the regions of $\mathrm{S}$. Bulgaria. The result of this is the achievement of higher emergy efficiency, which means higher annual turnover per emergy unit of the energy, capital and labor input, in the Greek regions, despite the Bulgarian advantage in the lower labor and services costs.

f The comparison of the sectors examined did not show any significant difference between them in terms of competitiveness, environmental distress, sustainability and eco-productivity. However, the mean value diagrams showed a dependency of the food/drink, the fabric/cloths and the chemical/plastics sectors on local conditions, in terms of labor and services. The chemical/plastics and metal/woods are the most pollutant sector, while the sector of electric/electronics appeared to be the most environmentally clean sector.

\section{Acknowledgements}

The raw data of this research paper has been collected in the context of the project entitled "Cross Border Implementation of Innovative Cost Cutting Technologies -CROSS INNO CUT", which was carried out within the frames of the European Territorial Cooperation Program Greece - Bulgaria (INTERREG IVA 2007-2013). All the above reflect only the authors' views; the European Union 
is not liable for any use that may be made of the information contained herein.

\section{REFERENCES}

[1] Georgiou, C., Komninos, N., Martzopoulou, A., Martinidis, G., Sefertzi, E., Tramantzas, K. Hybrid Innovation and the Future of Industry in Thessaloniki, Organisation for Planning and Environmental Protection of Thessaloniki, Yahoudis publications, Thessaloniki Greece, 2009.

[2] Geng, Y., Zhang, P., Ulgiati, S., Sarkis, J. Emergy analysis of an industrial park: The case of Dalian, China, Science of the Total Environment 408, pp. 5273-5283, 2010.

[3] Odum, H.T. Emergy of global process, Handbook of emergy evaluation, A compendioum of data for emergy computation, Gainsville, FL USA: Center for Environmental Policy, University of Florida, 2000

[4] Martzopoulou, A. Energy and environmental management on industrial concentrations, $\mathrm{PhD}$ thesis, Faculty of Engineering, Aristotle University of Thessaloniki, Greece, 2013

[5] Geng, Y., Côté, R. P. Scavengers and decomposers in an eco-industrial park, The International Journal of Sustainable Development \& World Ecology, 9(4), pp. 333-340, 2002.

[6] Martzopoulou, A. Emergy analysis of solar energy impact on the agri-food industry sustainability in Northern Greece, Proc. 1st International Conference on Agrifood Supply Chain Management \& Green Logistics - Supply Chain Management, May 27 - 30, Chalkidiki, Greece, 2015.

[7] Petrakis, P. The Economic Environment, Annual Report 2012, National Institute of Labour and Human Resources, Athens. pp. 3-18, 2013.

[8] Chrysanthopoulos, Sp. The Competitiveness Index of the World Economic Forum: A critical approach, Monthly journal of Labour Institute of the Greek General Confederation of Labour (INE/GSEE), Information, V. 206, 2013. 